Defraeye T., Houvenaghel G., Carmeliet J., Derome D. (2012), Numerical analysis of convective drying of gypsum boards, International Journal of Heat and Mass Transfer 55 (9-10), 2590-2600. http://dx.doi.org/10.1016/j.ijheatmasstransfer.2012.01.001

\title{
Numerical analysis of convective drying of gypsum boards
}

\author{
Thijs Defraeye ${ }^{\mathrm{a}, \mathrm{b} *}$, Geert Houvenaghel ${ }^{\mathrm{c}}$, Jan Carmeliet ${ }^{\mathrm{a}, \mathrm{d}}$, Dominique Derome ${ }^{\mathrm{e}}$
}

${ }^{a}$ Chair of Building Physics, Swiss Federal Institute of Technology Zurich (ETHZ), Wolfgang-Pauli-Strasse 15, 8093 Zürich, Switzerland

${ }^{b}$ VCBT / MeBioS, Department of Biosystems, Katholieke Universiteit Leuven, Willem de Croylaan 42, 3001 Heverlee, Belgium

${ }^{c}$ Lafarge Centre de Recherche, 95 rue Montmurier PB15, 389291 Saint Quentin Fallavier, France

${ }^{d}$ Laboratory for Building Science and Technology, Swiss Federal Laboratories for Materials Testing and Research (Empa), Überlandstrasse 129, 8600 Dübendorf, Switzerland

${ }^{e}$ Wood Laboratory, Swiss Federal Laboratories for Materials Testing and Research (Empa), Überlandstrasse 129, 8600 Dübendorf, Switzerland

\begin{abstract}
Convective drying of gypsum boards is investigated by numerical modelling, within the context of gypsum board manufacturing where enhancing processing efficiency, reducing energy usage and optimising product quality are essential. The aim of this parametric study is to provide a first step towards modelling of the drying process in an industrial drier by investigating the main factors impacting the drying process, such as the influence of air speed, turbulence intensity, approach flow temperature and heterogeneous drying conditions but also the influence of the paper liner on the drying process. Therefore, this study is performed for a simple configuration and at ambient air temperatures. In terms of air flow modelling, CFD simulations are performed in addition to the use of standard convective transfer coefficients. The sensitivity of the drying process to the air flow conditions is found to be limited for a gypsum board with a paper liner due to the high resistance of the paper liner to vapour transport, compared to the boundary layer resistance. Thus, guidelines for modelling drying of gypsum boards under representative manufacturing conditions conclude that detailed flow modelling is less critical to assess this specific drying problem. Instead, characterisation of the material transport properties at high temperatures is more relevant, particularly for the paper liner.
\end{abstract}

\section{Keywords}

Convective drying, gypsum board, heat and moisture transfer, manufacturing, convective transfer coefficient, paper liner.

\footnotetext{
* Corresponding author. Tel.: +32 (0)16321618; Fax: +32 (0)162966.

E-mail address: thijs.defraeye@biw.kuleuven.be
} 
Defraeye T., Houvenaghel G., Carmeliet J., Derome D. (2012), Numerical analysis of convective drying of gypsum boards, International Journal of Heat and Mass Transfer 55 (9-10), 2590-2600. http://dx.doi.org/10.1016/j.ijheatmasstransfer.2012.01.001

\section{Nomenclature}

$c_{p}$

specific heat capacity of air $(\mathrm{J} / \mathrm{kgK})$

$d_{P L}$

thickness of paper liner (m)

$D_{v a}$

binary diffusion coefficient between dry air and water vapour $\left(\mathrm{m}^{2} / \mathrm{s}\right)$

$g_{w}$ convective water vapour flux at the air-porous material interface $/ \mathrm{wall}\left(\mathrm{kg} / \mathrm{m}^{2} \mathrm{~s}\right)$

$g_{w, C D R P}$ drying rate during the CDRP $\left(\mathrm{kg} / \mathrm{m}^{2} \mathrm{~s}\right)$

$g_{w, S C}$

scaled drying rate (-)

$K$

moisture permeability (s)

$L$

gypsum board length (m)

$L_{v}$

heat of vaporisation $(\mathrm{J} / \mathrm{kg})$

$N u_{x}$

Nusselt number, based on the distance along the plate $x$, CHTC. $x / \lambda$

$\operatorname{Pr}$

Prandtl number, $v \rho c_{p} / \lambda$

$p_{c}$

capillary pressure $(\mathrm{Pa})$

$p_{v, a f}$

approach flow vapour pressure $(\mathrm{Pa})$

$p_{v, w}$

vapour pressure at the air-porous material interface $(\mathrm{Pa})$

$p_{v, s a t}$

saturation vapour pressure $(\mathrm{Pa})$

$q_{w}$

convective heat flux at the air-porous material interface/wall $\left(\mathrm{W} / \mathrm{m}^{2}\right)$

$R_{B L}$

boundary layer resistance $(\mathrm{m} / \mathrm{s}), 1 / \mathrm{CMTC}$

$R_{P L}$

vapour diffusion resistance of paper liner $(\mathrm{m} / \mathrm{s}), d_{P L} / \delta_{v, P L}$

$R e_{x}$

Reynolds number, based on $x$ and $U_{\infty}, U_{\infty} x / v$

$R_{v}$

specific gas constant of water vapour $(\mathrm{J} / \mathrm{kgK})$

Sc

Schmidt number, $v / D_{v a}$

Sh

Sherwood number, CMTC.L/ $\delta_{v}$

$t_{S C}$

scaled drying time $\left(\mathrm{kg} / \mathrm{m}^{2}\right)$

$T$

temperature $(\mathrm{K})$

$t$

time (s)

$T_{a f}$

approach flow temperature $(\mathrm{K})$

$T_{w}$

temperature at the air-porous material interface/wall (K)

$T_{w b}$

wet bulb temperature $(\mathrm{K})$

$U_{b}$

bulk air speed $(\mathrm{m} / \mathrm{s})$

$U_{\infty}$

free stream air speed $(\mathrm{m} / \mathrm{s})$

w

moisture content of gypsum board $\left(\mathrm{kg} / \mathrm{m}^{3}\right)$

$w_{\text {ini }}$

$w_{i n i}^{*}$

initial moisture content of gypsum board $\left(\mathrm{kg} / \mathrm{m}^{3}\right)$

initial moisture content of gypsum board $(\mathrm{kg} / \mathrm{kg})$

$w_{\text {cap }}$

capillary moisture content of gypsum board $\left(\mathrm{kg} / \mathrm{m}^{3}\right)$

$x$

coordinate $(\mathrm{m})$

$y$

coordinate $(\mathrm{m})$

dimensionless wall (normal) distance (-), $\left(\tau_{w} / \rho\right)^{1 / 2} y_{P} / v$

distance (normal) of cell centre point $P$ of wall-adjacent cell to the wall (m) 
Defraeye T., Houvenaghel G., Carmeliet J., Derome D. (2012), Numerical analysis of convective drying of gypsum boards, International Journal of Heat and Mass Transfer 55 (9-10), 2590-2600. http://dx.doi.org/10.1016/j.ijheatmasstransfer.2012.01.001

\section{Greek symbols}

$\delta_{v}$

$\delta_{v, P L}$

$\lambda$

$v$

$\rho$

$\tau_{w}$

\section{Subscripts}

af

avg

BL

BPL

cap

CDRP

GB

ini

SC

$\mathrm{v}$

W

wb

PL

\section{Abbreviations}

CDRP

CFD

CHTC

CMTC

CTC

DDRP

HAM

LRNM

RH

TI water vapour diffusion coefficient of air (s)

water vapour diffusion coefficient of paper liner (s)

thermal conductivity of air $(\mathrm{W} / \mathrm{mK})$

kinematic viscosity of air $\left(\mathrm{m}^{2} / \mathrm{s}\right)$

air density $\left(\mathrm{kg} / \mathrm{m}^{3}\right)$

wall shear stress $\left(\mathrm{kg} / \mathrm{ms}^{2}\right)$

approach flow

average

boundary layer

below paper liner

capillary

constant drying rate period

gypsum board

initial

scaled

water vapour

wall/ air-porous material interface

wet bulb

paper liner

constant drying rate period

computational fluid dynamics

convective heat transfer coefficient

convective mass transfer coefficient

convective transfer coefficient

decreasing drying rate period

heat-air-moisture

low-Reynolds number modelling

relative humidity

turbulence intensity 
Defraeye T., Houvenaghel G., Carmeliet J., Derome D. (2012), Numerical analysis of convective drying of gypsum boards, International Journal of Heat and Mass Transfer 55 (9-10), 2590-2600. http://dx.doi.org/10.1016/j.ijheatmasstransfer.2012.01.001

\section{Introduction}

Convective drying of freshly cured gypsum boards is an important process phase in their manufacturing process. Optimisation of this drying process is required to enhance processing efficiency, in terms of energy usage and production time, without compromising the product quality, for example by strong heterogeneous drying or excessive thermal gradients. Most research on combined heat and mass transport in gypsum boards focussed on its application regarding fire resistance [1-9], thus for high board temperatures $\left(>100^{\circ} \mathrm{C}\right)$ and only accounting for water vapour transport. To the knowledge of the authors, experimental and numerical research on gypsum board drying, i.e. of boards containing a large excess of liquid (not chemically bound) water, is very limited (e.g. [10]). Therefore, a study on gypsum board drying by means of numerical modelling is undertaken in this paper to identify the main characteristics of the drying process and to propose focus points for future research.

Many numerical modelling approaches have been developed to model drying of porous materials by solving coupled heat and moisture transport inside the material, such as pore network models (e.g. [11-13]) or macroscopic models (e.g. [14-15]), where mostly low temperature applications $\left(<100^{\circ} \mathrm{C}\right)$ are considered. Obtaining the required moisture transport properties by experimental characterisation is particularly difficult at high temperatures. Regarding boundary conditions, the convective heat and mass exchange with the external air flow is often modelled by means of convective heat and mass transfer coefficients, i.e. CHTCs and CMTCs, respectively. These convective transfer coefficients (CTCs) are used to relate the convective heat and moisture flux normal to the wall $\left(q_{w}\right.$ and $\left.g_{w}\right)$, i.e. at the air-porous material interface, to the difference between the temperature $\left(T_{w}\right)$ or vapour pressure $\left(p_{v, w}\right)$ at the wall surface and a reference temperature or vapour pressure, for example the approach flow conditions $\left(T_{a f}\right.$ and $\left.p_{v, a f}\right)$ :

$$
\begin{aligned}
& C H T C=\frac{q_{w}}{T_{w}-T_{a f}} \\
& C M T C=\frac{g_{w}}{p_{v, w}-p_{v, a f}}
\end{aligned}
$$

The fluxes are assumed positive when departing from the porous material. These CTCs can actually be considered as the inverse of the boundary layer resistances to heat and mass transfer. They are however a simplified way of accounting for the flow field: (1) CTCs are often estimated by means of empirical correlations dependent on the air speed, where these correlations were mostly derived for simplified configurations, such as flat plates; (2) The spatial variation of the CTCs along the surface and especially their temporal variation are often not accounted for. Due to these simplifications, the use of CTCs can compromise the accuracy of fluid-side convective heat and mass transfer predictions for certain applications, one of them being convective drying of (un)saturated porous materials.

In this study, the convective drying of wet gypsum boards is investigated by numerical modelling, in the context of improving gypsum board manufacturing. The aim of this parametric study is to provide a first step towards modelling of the drying process in an industrial drier by investigating the main factors impacting the drying process, both related to the gypsum board as well as to the air flow. Therefore, this first parametric exploration is performed using a simple configuration and simple conditions of the drying process, such as material properties measured at ambient temperature and air temperatures lower than the ones of the actual industrial process. Heat- 
Defraeye T., Houvenaghel G., Carmeliet J., Derome D. (2012), Numerical analysis of convective drying of gypsum boards, International Journal of Heat and Mass Transfer 55 (9-10), 2590-2600. http://dx.doi.org/10.1016/j.ijheatmasstransfer.2012.01.001

air-moisture (HAM) modelling is used to model the transport in the board. In terms of convective boundary conditions, in addition to the use of standard CTCs, air flow modelling with computational fluid dynamics (CFD) is also performed. For the gypsum board, the focus is mainly on the influence of the paper liner on the drying process, where for the air flow, the influence of air speed, turbulence intensity, approach flow temperature and heterogeneous drying conditions is investigated.

\section{Background}

To indicate the context of this study, a typical industrial gypsum-board drier system is briefly discussed. In such a drier (Figure 1), gypsum boards, composed of 9 to $25 \mathrm{~mm}$ of freshly cured wet gypsum (calcium sulphate), containing an excess of water, between two different liners of plasterboard paper, are stacked horizontally in several parallel layers at a certain distance $(\sim 0.2 \mathrm{~m})$ between each other. The boards move on a roller system through the drier at low speeds $(\sim 0.05 \mathrm{~m} / \mathrm{s})$. Hot dry air $\left(\sim 250^{\circ} \mathrm{C}\right)$ is blown in between the gypsum boards from the sides. Since all sides of the drier are closed, the air flow is forced towards the inlet and outlet of the drier and is thereby mainly parallel to the direction of the gypsum board movement, leading to counter-current air flow towards the inlet, i.e. opposite to the gypsum board movement, and co-current air flow towards the drier outlet, typically at air speeds of $10 \mathrm{~m} / \mathrm{s}$. Due to the energy needed for the evaporation of the excess water from the gypsum board (heat of vaporisation), the air temperature towards the drier inlet and outlet decreases and the relative humidity of the air increases. From measurements, it is known that this evaporation keeps the temperatures in the gypsum boards below $100^{\circ} \mathrm{C}$. Upon entry in the drier, the gypsum board temperature is slightly above ambient temperature.

\section{Numerical modelling study}

\subsection{Configuration}

In this study, a simple configuration is used to evaluate the convective drying of gypsum boards (Figure 2), which is built up in such a way that it allows investigating the main factors impacting the drying process, such as the air speed, turbulence intensity, approach flow temperature and heterogeneous drying conditions, i.e. local variations in CTCs. Ambient temperatures are applied in this study, by which the material properties can also be determined at such temperatures. Channel flow is assumed in between the gypsum boards (thickness $=12 \mathrm{~mm}$ ), which are spaced vertically at $0.23 \mathrm{~m}$, with a bulk air speed $\left(U_{b}\right)$ of $10 \mathrm{~m} / \mathrm{s}$ in between the channels. The temperature and relative humidity $(\mathrm{RH})$ of the approach flow air are taken $20^{\circ} \mathrm{C}$ and $5 \%$ respectively (approach flow conditions, $T_{a f}$ and $R H_{a f}$ ), thus representing dry air. Since the flow between the gypsum boards is mainly parallel to the direction of movement of the boards and due to the large aspect ratio of the drier, i.e. channel width ( $10 \mathrm{~m}$, out of plane direction in Figure 2$)$ to channel height $(0.23 \mathrm{~m})$, a two-dimensional configuration is used within the context of gypsum board manufacturing. The influence of the movement speed of the boards ( $0.05 \mathrm{~m} / \mathrm{s}$ ) on the drying process can be neglected due to the high air speeds ( $10 \mathrm{~m} / \mathrm{s})$. The gypsum boards are initially assumed to be quasi capillary saturated $\left(w_{i n i}=291 \mathrm{~kg} / \mathrm{m}^{3}, w^{*}{ }_{i n i}=0.384 \mathrm{~kg} / \mathrm{kg}\right)$ at a temperature of $20^{\circ} \mathrm{C}$, where the hydration reaction is considered to be completed. The capillary moisture content $\left(w_{\text {cap }}=295 \mathrm{~kg} / \mathrm{m}^{3}\right)$ is obtained from a free water uptake test. A gypsum board with a length of only $0.3 \mathrm{~m}$ is chosen since the aim of this study is on investigating some basic characteristics of the drying process, such as the influence of local spatial variations in CTCs, rather than on modelling the entire industrial drier. Although the flow in the channels 
Defraeye T., Houvenaghel G., Carmeliet J., Derome D. (2012), Numerical analysis of convective drying of gypsum boards, International Journal of Heat and Mass Transfer 55 (9-10), 2590-2600. http://dx.doi.org/10.1016/j.ijheatmasstransfer.2012.01.001

will be partially developed in an industrial drier, resulting in a relatively small spatial variation of the CTCs along the boards, a uniform air speed profile is assumed close to the leading edge of the board in the simulations, leading to high CTCs here. This allows analysing the impact of local spatial variations in CTCs, for example resulting from an ill-conditioned flow field in the drier (e.g. at the air supply, see Figure 1), on the drying process of the boards by means of the simple configuration. These spatial CTC variations can result in heterogeneities in the local drying rate which can lead to a varying product quality. Although this simple configuration is not representing an actual industrial drier, it allows (and is used in this study) to investigate specific characteristics of the gypsum board drying process, e.g. the influence of spatial CTC variations.

This configuration is analysed numerically by modelling the heat and moisture transport in the gypsum board with a porous-material (HAM) model, where the convective boundary conditions at the interface are provided either using constant CTCs or by CFD modelling. Note that radiative heat transfer is not accounted for since opposing gypsum boards are assumed to be at approximately the same temperature. The computational domains used for numerical modelling of the gypsum board and air flow are specified in Figure 3, together with the imposed boundary conditions. Symmetry boundary conditions are used to simplify the proposed configuration (Figure 2), by which the paper liners are assumed identical on both sides. The boundary conditions specified in Figure 3 are those of the reference case, whereas other conditions are evaluated in section 4 . In the following sections, modelling of air flow and transport in the gypsum board are discussed in detail.

\subsection{Air flow modelling}

The convective heat and mass transport at the air-porous material interface is modelled with two different approaches: (1) a one-dimensional approach, using constant CTC values, which are obtained from empirical flat plate correlations; (2) a two-dimensional approach, using spatially varying CTCs along the board, which are obtained with CFD. Such spatial variation of the CTCs allows identifying two-dimensional effects in the drying of the board.

\subsubsection{Constant CTCs}

Estimates of CTCs are often obtained by means of empirical flat plate correlations with the air speed. A typical correlation for the CHTC for turbulent flat plate flow is [16]:

$N u_{x}=0.032 \operatorname{Re}_{x}^{0.8} \operatorname{Pr}^{0.43}$

where $N u_{x}$ is the Nusselt number, based on the distance along the plate $(x), \operatorname{Pr}$ is the Prandtl number of air and $R e_{x}$ is the Reynolds number, based on $x$ and the free stream air speed $\left(U_{\infty}\right)$ :

$N u_{x}=\frac{C H T C \cdot x}{\lambda}$

$\operatorname{Pr}=\frac{v \rho c_{p}}{\lambda}$

where $\rho$ is the air density, $\lambda$ is its thermal conductivity, $c_{p}$ is its specific heat capacity and $v$ is its kinematic viscosity. The constant CTC values, used in the one-dimensional approach, are calculated from this correlation, where the average value over the gypsum board is used. For $U_{\infty}=10 \mathrm{~m} / \mathrm{s}$ and a board length $L=0.3 \mathrm{~m}$, a CHTC 
Defraeye T., Houvenaghel G., Carmeliet J., Derome D. (2012), Numerical analysis of convective drying of gypsum boards, International Journal of Heat and Mass Transfer 55 (9-10), 2590-2600. http://dx.doi.org/10.1016/j.ijheatmasstransfer.2012.01.001

of $50.3 \mathrm{~W} / \mathrm{m}^{2} \mathrm{~K}$ is obtained. The CMTC is often estimated out of the CHTC by using the heat and mass transfer analogy:

$$
\frac{N u}{S h}=\left(\frac{\operatorname{Pr}}{S c}\right)^{1 / 3}
$$

where $S h$ is the Sherwood number (average over the board) and $S c$ is the Schmidt number for air:

$$
\begin{aligned}
& S h=\frac{C M T C \cdot L}{\delta_{v}} \\
& S c=\frac{v}{D_{v a}}=\frac{v}{\delta_{v} R_{v} T}
\end{aligned}
$$

where $\delta_{v}$ is the vapour diffusion coefficient of air, $D_{v a}$ is the binary diffusion coefficient between water vapour and dry air, $R_{v}$ is the specific gas constant for water vapour, $c_{p}$ is the specific heat capacity of air and $T$ is the temperature in Kelvin. Corresponding to a CHTC of $50.3 \mathrm{~W} / \mathrm{m}^{2} \mathrm{~K}$, a CMTC of $3.58 \times 10^{-7} \mathrm{~s} / \mathrm{m}$ is obtained when combining Eqs.(4)-(8):

$C M T C=\left(\frac{\delta_{v}}{\lambda}\right)^{2 / 3} \frac{C H T C}{\left(\rho c_{p} R_{v} T\right)^{1 / 3}}$

\subsubsection{CFD modelling}

The computational domain for the CFD simulations is presented in Figure 3. The inlet boundary is taken close to the leading edge of the gypsum board to have a quasi undeveloped velocity boundary layer here, resulting in high CTC gradients. A sufficiently long downstream channel section is modelled to avoid an influence of the outlet boundary condition on the air flow in the vicinity of the gypsum board. Although channel flow is modelled in the CFD simulations, the boundary layer development along the gypsum board will resemble that of a flat plate since the channel entrance length is quasi zero (uniform approach flow) and since the gypsum board (plate) length is short. Therefore, comparison with flat plate CTC correlations can be justified, and it will be shown later on that they agree very well.

Only heat transfer is accounted for in the CFD simulations, as the CMTC is determined afterwards with the heat and mass transfer analogy, which is a commonly used approach for convective transfer problems. At the inlet, a uniform velocity profile is imposed with a bulk air speed $\left(U_{b}\right)$ of $10 \mathrm{~m} / \mathrm{s}$, resulting in a Reynolds number of $1.6 \times 10^{5}$, based on $U_{b}$ and the channel height. Thereby, flow is turbulent, where a turbulence intensity (TI) of $1 \%$ is assumed. The temperature of the approach flow air is taken $20^{\circ} \mathrm{C}$. At the outlet, a zero static pressure is imposed. The channel wall is modelled as a no-slip boundary with zero roughness. The air-porous material interface is given a temperature of $30^{\circ} \mathrm{C}$, which could be chosen arbitrarily since the resulting CHTC is quasi independent of the thermal boundary conditions if buoyancy is not taken into account (see below). The remainder of the channel wall is taken adiabatic. At the top boundary, symmetry is imposed which assumes that the normal velocity component and the normal gradients at the boundary are zero.

An appropriate grid is built, based on a grid sensitivity analysis, consisting of $8.0 \times 10^{3}$ quadrilateral control volumes (also called cells, 267 in $\mathrm{x}$-direction, 30 in y-direction). The discretisation error is estimated to be below $1 \%$. Since low-Reynolds number modelling (LRNM) is used to resolve the boundary layer instead of wall 
Defraeye T., Houvenaghel G., Carmeliet J., Derome D. (2012), Numerical analysis of convective drying of gypsum boards, International Journal of Heat and Mass Transfer 55 (9-10), 2590-2600. http://dx.doi.org/10.1016/j.ijheatmasstransfer.2012.01.001

functions, a high cell density in the wall-normal direction and a small $y^{+}$value (dimensionless wall distance) of the wall-adjacent cell is required $\left(y^{+} \approx 1\right)$, where $y^{+}$is defined as:

$y^{+}=\frac{\sqrt{\frac{\tau_{w}}{\rho}} y_{P}}{v}$

where $y_{P}$ is the distance (normal) of centre point $\mathrm{P}$ of the wall-adjacent cell to the wall and $\tau_{w}$ is the shear stress at the wall. The highest $y^{+}$values are attained at the inlet of the computational domain but are smaller than 2.

The simulations are performed with the CFD code Fluent 12, which uses the control volume method. Steady Reynolds-averaged Navier-Stokes is used in combination with a turbulence model. The realizable k- $\varepsilon$ turbulence model [17] is used together with LRNM to resolve the boundary layer, for which the one-equation Wolfshtein model [18] is used. LRNM is preferred over the commonly-used wall functions [19] for reasons of improved accuracy for heat transfer [20-22], since wall functions model the lower part of the boundary layer instead of resolving it explicitly. This realizable k- $\varepsilon$ model with LRNM was recently evaluated in a CFD validation study for convective heat transfer at the surfaces of a cube in turbulent channel flow [22], where good agreement with experimental data was obtained.

Due to the very low Richardson numbers in the channel $(<<<1)$, buoyancy effects could be neglected. Since only forced convection is considered, the CHTC is quasi independent of the imposed thermal boundary conditions. Second-order discretisation schemes are used throughout. The SIMPLE algorithm is used for pressure-velocity coupling. Pressure interpolation is second order. Convergence was assessed by monitoring the velocity, turbulent kinetic energy and temperature on specific locations in the flow field and heat fluxes at the porous material surface. Thereby, specifying limits for residuals, i.e. to evaluate convergence, was not required for these simulations.

\subsection{Gypsum board modelling}

The gypsum board is modelled by means of a porous-material (HAM) model, which calculates heat, air and moisture (liquid and vapour) transport in porous materials. Air transport is not taken into account in this study since its influence is considered to be limited for this specific problem. Since the porous structure of the gypsum is already formed when the boards enter the drier, classical HAM theory can be applied. Details on the used HAM model can be found in Janssen et al. [15]. Transport in porous materials is modelled using the continuum approach, where macroscopic experimentally-determined material properties are required. Accurate HAM simulations thereby strongly depend on a reliable determination of these material properties. Previous studies however indicated a significant spread and thus uncertainty on these properties when comparing round-robin testing results from different laboratories on different samples of a specific gypsum board [23]. Therefore, the sorption isotherm (moisture content $w$ as a function of RH, Figure 4a), vapour permeability and liquid water uptake were determined for the two components of gypsum board separately, i.e. gypsum core and paper, and also for the gypsum board as a whole. Using the method of Carmeliet and Roels [24], the moisture permeability $(K)$ over the entire capillary pressure range ( $p_{c}$, pressure difference between the gaseous and liquid phase) was calculated, as shown in Figure $4 \mathrm{~b}$. The moisture retention curve ( $w-p_{c}$ relation), scaled with $w_{\text {cap }}$, is also included 
Defraeye T., Houvenaghel G., Carmeliet J., Derome D. (2012), Numerical analysis of convective drying of gypsum boards, International Journal of Heat and Mass Transfer 55 (9-10), 2590-2600. http://dx.doi.org/10.1016/j.ijheatmasstransfer.2012.01.001

here. At low capillary pressures (high RH), moisture transport occurs mainly by liquid transport and at higher capillary pressures (low RH), it occurs by vapour transport. Since the paper liner was found to show quasi no liquid water uptake, due to the presence of sizing agents added during paper production, the moisture transport at low capillary pressures also occurs by vapour transport. The strong difference in vapour transport properties of paper and gypsum required modelling of the actual layers of the board, i.e. paper-gypsum-paper, since considering the board as one composite material would prevent capturing the transport phenomena accurately. Note that the contact resistances between gypsum and paper are assumed to be negligible.

The most important assumptions, relevant for this study, of the used HAM model are that: (1) shrinking and swelling is not accounted for; (2) liquid transfer due to thermal gradients is neglected; (3) the pressure of the gaseous phase is constant and equal to the atmospheric pressure; (4) temperatures are well below $100^{\circ} \mathrm{C}$. Also noteworthy, for this implementation, is that material properties are not a function of temperature. Given these assumptions and limitations, the accuracy of the HAM simulations at ambient approach flow air temperatures can be assured.

Apart from a typical gypsum board, which has a paper liner on both sides (thickness $d_{P L}=0.27 \mathrm{~mm}$ ), a gypsum board without a paper liner is also evaluated to assess the influence of the paper liner. In the numerical model without the paper liner, the thickness of the board is also taken $0.006 \mathrm{~m}(0.012 \mathrm{~m}$ accounting for symmetry). The symmetry boundary conditions in the centre of the gypsum board correspond to adiabatic and impermeable conditions. To avoid lateral heat and moisture transport at the sides of the board, adiabatic and impermeable conditions are imposed (see Figure 3).

Two computational grids are built, namely for the 1D approach, using constant CTCs, and for the 2D approach, using spatially varying CTCs from CFD (see section 3.2.2). These grids are built based on a grid sensitivity analysis and consist of 20 finite elements ( 1 in x-direction, 20 in y-direction) and 4000 finite elements (200 in xdirection, 20 in y-direction) for the 1D and 2D model, respectively. The discretisation error is estimated to be below $1 \%$. In the next section, the influence of various air flow and gypsum board related parameters on the drying process of gypsum board is investigated by a parametric study, but first the characteristics of the drying process are discussed.

\section{Results}

\subsection{Drying process}

\subsubsection{Influence of paper liner}

In this section, the influence of the paper liner on the drying process is evaluated by using the 1D HAM model with constant CTCs. The influence of spatially varying CTCs on the drying process will be assessed in section 4.1.2. In Figure 5, the impact of the paper liner is shown by comparing the drying rate, temperature and $\mathrm{RH}$ at the surface (subscript ${ }_{\mathrm{w}}$ ) of a gypsum board with paper liner (GB w paper) and without paper liner (GB w/o paper). The drying rate is defined here as the mass flow rate per unit surface, i.e. the moisture flux at the surface $\left(g_{w}\right)$. Note that the reported drying rates and times are not representative for an industrial drier due to the low air temperature used in the simulations. All simulations were performed for a period of $25 \mathrm{~h}$. 
Defraeye T., Houvenaghel G., Carmeliet J., Derome D. (2012), Numerical analysis of convective drying of gypsum boards, International Journal of Heat and Mass Transfer 55 (9-10), 2590-2600. http://dx.doi.org/10.1016/j.ijheatmasstransfer.2012.01.001

The gypsum board without a paper liner shows a short constant drying rate period (CDRP), as indicated by the arrow in Figure 5. The CDRP, where the porous material is actually in an equilibrium state, is characterised by a constant drying rate, a RH of quasi $100 \%$ at the surface $\left(p_{v, w} \approx p_{v, s a t}\left(T_{w}\right)\right.$, with $p_{v, \text { sat }}$ the saturation vapour pressure at $\left.T_{w}\right)$ and a quasi constant material temperature, equal to the wet bulb temperature $\left(T_{w b}\right)$. As evaporation occurs at the air-porous material interface, the drying rate is characterised by the air flow conditions and not by the material transport properties. Nevertheless, the material transport properties do affect the length of the CDRP, since it is dependent on the liquid transport to the surface. Since conductive heat flow into the material is very small during the CDRP, the convective heat flow towards the material is quasi entirely used to evaporate the liquid water at the surface, leading to following relation:

$q_{w} \approx L_{v} g_{w}$

where $L_{v}$ is the heat of vaporisation $\left(\approx 2.5 \times 10^{6} \mathrm{~J} / \mathrm{kg}\right)$. Using Eqs.(1)-(2), following relation can be obtained.

$\operatorname{CHTC}\left(T_{w b}-T_{a f}\right)=L_{v} \operatorname{CMTC}\left(p_{v, s a t}\left(T_{w b}\right)-p_{v, a f}\right)$

This expression can be solved to $T_{w b}$ if the ratio CMTC/CHTC is known. This CTC ratio can be determined from the heat and mass transfer analogy (Eq.(9)) and is equal to about 7.1 x10 $0^{-9}$. Although this ratio is slightly dependent on the temperature, related to the material properties, a constant ratio is used in this study. For $T_{a f}=$ $20^{\circ} \mathrm{C}$ and $R H_{a f}=5 \%$, a wet bulb temperature of $5.7^{\circ} \mathrm{C}$ is obtained using Eq.(12) (indicated by the horizontal grey line in Figure 5). Its good agreement with the temperature predictions of the HAM model (during the CDRP, GB w/o paper) indicates that the HAM model represents the drying process accurately. Note however that this agreement was partially enforced since the CTC ratio was imposed $\left(=7.1 \times 10^{-9}\right.$ from CHTC $=50.3 \mathrm{~W} / \mathrm{m}^{2} \mathrm{~K}$ and $\mathrm{CMTC}=3.58 \times 10^{-7} \mathrm{~s} / \mathrm{m}$ ). If another CTC ratio is used, e.g. from experimental data, a slightly different $T_{w b}$ would be predicted by the HAM model. After the short CDRP, the gypsum board without a paper liner dries out at the surface, where the decreasing drying rate period (DDRP) sets in. A drying front progresses towards the inside of the material where moisture is removed by vapour diffusion from this drying front towards the air-porous material interface. The DDRP is characterised by a decreasing drying rate and an increase in surface temperature (see Figure 5) since the "dry" outer porous-material layer forms an additional resistance to liquid water removal from the material core towards the interface, in addition to the boundary layer resistance. During the CDRP, moisture is present at the interface and its removal and the drying process are determined by the air flow, whereas during the DDRP, they are controlled by the transport of moisture in the material towards the surface where it is removed, by which the drying rate is much less sensitive to the convective boundary conditions.

The board with a paper liner shows a significantly lower drying rate ( one order of magnitude), a higher surface temperature and a RH far below $100 \%$ at the surface. Nevertheless, a constant drying rate and surface temperature are found over a long period of time, resembling a CDRP, but with a much lower RH at the surface. The surface below the paper liner however remains wet $(\mathrm{RH} \approx 100 \%)$. This apparent CDRP is related to the paper, which was found to be hydrophobic, by which no liquid transport in the paper could be observed nor measured, and therefore the maximal moisture conductivity of the paper equals the vapour conductivity at high RH. Although the gypsum board remains wet underneath the paper liner, moisture transport through the paper liner to the air-porous material interface thereby only occurs by vapour diffusion. The paper liner thereby acts as 
Defraeye T., Houvenaghel G., Carmeliet J., Derome D. (2012), Numerical analysis of convective drying of gypsum boards, International Journal of Heat and Mass Transfer 55 (9-10), 2590-2600. http://dx.doi.org/10.1016/j.ijheatmasstransfer.2012.01.001

an additional resistance against moisture removal from the board, i.e. in addition to the boundary layer resistance, inducing much longer drying times. The boundary layer resistance to vapour transfer $\left(R_{B L}\right)$, namely the inverse of the CMTC, is compared to the vapour diffusion resistance of the paper liner $\left(R_{P L}=d_{P L} / \delta_{v, P L}\right)$ in Figure $6 \mathrm{a}$ as a function of the paper liner thickness. Since the vapour diffusion coefficient of paper is dependent on the RH (Figure 4b), Figure $6 a$ includes vapour diffusion resistances at different $\mathrm{RH}(20 \% \leq \mathrm{RH} \leq 100 \%)$. The paper liner resistance is clearly much larger than the boundary layer resistance, even for very small liner thicknesses. Thereby, the sensitivity of the drying rate of a gypsum board with a paper liner to the flow field is rather limited, which seems to remove the need for detailed air flow modelling, as discussed more in detail in section 4.1.2. Note that if the vapour diffusion resistance of the paper liner would not be dependent on its RH, which is not constant throughout the liner, this resistance could be combined with that of the boundary layer in an equivalent resistance or transfer coefficient. Also note that the term CDRP will also be used for the board with paper, although the $\mathrm{RH}$ at the surface is not $100 \%$.

The influence of the paper liner thickness on the drying rate is presented in Figure 6b, where the gypsum board drying rate during the CDRP, normalised by this drying rate for a paper liner of $0.27 \mathrm{~mm}$, is shown. Although the vapour diffusion resistance of the paper liner increases linearly with the paper thickness, its influence on the drying rate is non linear due to the RH dependency of the vapour diffusion coefficient. The gypsum board drying rate is clearly to a large extent dependent on the thickness and vapour diffusion properties of the paper, which indicates that such simulations require an accurate characterisation of the paper's material properties. Note that determining the thickness of the paper unambiguously is not that straightforward, due to some spread on its mean value and its compressibility, which will introduce an uncertainty on the actual thickness and thus on the drying rate, due to its large sensitivity on the paper thickness.

Comparing drying processes, as in Figure 5, can be difficult if the (CDRP) drying rates differ significantly in magnitude, where the drying process reflects on the length of the CDRP and DDRP and the transition between both. A better comparison is possible by using the scaled drying rate $\left(g_{w, S C}\right)$ and drying time $\left(t_{S C}\right)$, which are scaled with the drying rate during the $\operatorname{CDRP}\left(g_{w, C D R P}\right)$ :

$$
g_{w, S C}=\frac{g_{w}}{g_{w, C D R P}}
$$

$t_{S C}=g_{w, C D R P} t$

The reasons for applying this scaling are that: (1) all drying rate curves coincide during the CDRP, which allows comparison of processes with significantly different magnitudes of drying rates; (2) the surface below the scaled drying rate curve (integral of $g_{w, S C}$ to $t_{S C}$ ) still represents the amount of water which evaporated from the gypsum board (integral of $g_{w}$ to $t$ ), where the total amount of water is equal for all boards in this study, namely the initial moisture content. Thereby, a better comparison of different drying processes is possible: the scaled curves (corresponding to Figure 5) in Figure 7 indicate that the gypsum board with a paper liner clearly shows a longer CDRP and a much shorter DDRP. 
Defraeye T., Houvenaghel G., Carmeliet J., Derome D. (2012), Numerical analysis of convective drying of gypsum boards, International Journal of Heat and Mass Transfer 55 (9-10), 2590-2600. http://dx.doi.org/10.1016/j.ijheatmasstransfer.2012.01.001

Finally, the moisture saturation level in the gypsum board (1D HAM model with constant CTCs) of gypsum board with and without a paper liner is shown in Figure 8 as a function of the distance from the interface for different moments in time. Thereby, it is clear that the moisture distribution inside the gypsum layer is much more uniform when a paper liner is present, due to the overall lower drying rate.

\subsubsection{Influence of air flow modelling}

Prior to the analysis of the impact of spatially varying CTCs on the drying process, the CTCs predicted by CFD are assessed. The CHTC distribution along the gypsum board is presented in Figure 9, together with the empirical correlation (Eq.(3)), which was used to estimate the CTCs for the 1D HAM model. The two distributions are very similar, due to the correspondence of the CFD configuration (Figure 3 ) to that of a flat plate, resulting in an average CHTC ( $\mathrm{CHTC}_{\text {avg }}$ ) of $49.2 \mathrm{~W} / \mathrm{m}^{2} \mathrm{~K}$ for CFD. Since CFD is used here to estimate CTCs for a quite simple configuration, i.e. channel flow, its advantages for gypsum board drying predictions, compared to empirical flat plate correlations, is not clearly expressed. Nevertheless, CFD could be very useful when assessing CTCs for more complex configurations, e.g. for detailed modelling of entire drier systems, when flat plate correlations are not applicable anymore. In such cases, 2D HAM simulations applying flat plate CTC correlations on the one hand, and those from CFD on the other hand could yield significantly different results. In this study, such (simulation and CTC) differences would be very small (Figure 9), which is why only 2D HAM simulations using CTC information from CFD were performed. The added value of CFD simulations for this study is however that they allow investigating the influence of the turbulence intensity (imposed at the inlet) on the CTCs. The impact of the turbulence level on the CHTC distribution and magnitude is shown in Figure 10. Increased turbulence intensity clearly leads to an increased CHTC. Figure $10 \mathrm{~b}$ also shows the influence of the free stream air speed on the $\mathrm{CHTC}_{\text {avg }}$ magnitude, indicating the power law dependency of Eq.(3). In section 4.2.2, the influence of these air flow parameters, represented by CTCs, on the gypsum board drying rate is investigated.

The influence of spatially varying CTCs over the air-porous material interface on gypsum board drying, which is a specific focus of this study, is evaluated by means of the 2D HAM model. Therefore, the spatial CTC distribution over the board, obtained by CFD, is used. The scaled drying rates, as a function of scaled time, are shown in Figure 11 for 1D (constant CTCs from flat plate correlation) and 2D modelling, i.e. for constant and spatially varying CTCs, for gypsum board with and without a paper liner. Note that the drying rates of the 2D simulation are scaled with $g_{w, C D R P}$ of the 1D simulation, thereby indicating that the CDRP drying rate for the 2D simulations is approximately equal to that of the 1D simulations, except for the gypsum board without paper liner, since here no CDRP is found. In Figure 12, the drying rates of gypsum board with and without a paper liner are shown for 2D HAM modelling, normalised with the CDRP drying rate ( $\left.g_{w, C D R P}\right)$ of the 1D simulation, as a function of time at different locations on the gypsum board surface ( $x$ coordinate).

Without a paper liner, a significant difference in overall drying rate is found for the 1D and 2D model (Figure 11), where a distinct spatial variation (two-dimensionality) could be noticed in the local drying rates (and moisture gradients inside the gypsum layer) for the 2D model (Figure 12a) as the board dries out faster at the leading edge. Due to the large vapour transfer resistance of the paper liner, compared to that of the boundary 
Defraeye T., Houvenaghel G., Carmeliet J., Derome D. (2012), Numerical analysis of convective drying of gypsum boards, International Journal of Heat and Mass Transfer 55 (9-10), 2590-2600. http://dx.doi.org/10.1016/j.ijheatmasstransfer.2012.01.001

layer, the impact of spatially varying CTCs on the overall drying rate is limited for a gypsum board with a paper liner (Figure 11), where limited variation in local drying rates (and moisture gradients inside the gypsum layer) is found for the 2D model (Figure 12b). Thereby, modelling spatially varying CTCs is actually not required for gypsum boards with a paper liner. In the next section, the influence of different air flow and porous material parameters on gypsum board drying will be investigated by means of a parametric study. To allow a better comparison of gypsum boards with and without a paper liner, one-dimensional CTC modelling is used instead of two-dimensional CTC modelling so the drying rate is not influenced by two-dimensional effects, since these are significantly different for boards with and without a paper liner. Note that the focus in the next section will be mainly on gypsum boards with a paper liner.

\subsection{Parametric study}

\subsubsection{Gypsum board thickness}

Since gypsum boards are often produced in different thicknesses, a comparison of the drying process is made between a gypsum board (with paper liner) of $12 \mathrm{~mm}$ and $25 \mathrm{~mm}$ in Figure 13, where the scaled drying rate is presented as a function of scaled time. Since the initial moisture content of the $25 \mathrm{~mm}$ board, compared to the 12 $\mathrm{mm}$ case, is larger by a factor $25 / 12$, the scaled time for the $25 \mathrm{~mm}$ board is multiplied by a factor $12 / 25$ so the surface below the drying rate curve (integral of $g_{w, S C}$ to $t_{S C}$ ) is equal to that of the $12 \mathrm{~mm}$ board, which allows a better comparison. Note that the same $g_{w, C D R P}$ is found for both boards. Both drying processes are very similar, where the CDRP ends faster for the $25 \mathrm{~mm}$ board, leading to a longer (scaled) drying time. In the next sections, the influence of air flow modelling parameters is discussed.

\subsubsection{Air flow}

The sensitivity of gypsum board drying to the air speed is investigated in Figure 14 (1D model with constant CTCs). The CTCs are determined from the flat plate correlation (Eq.(3)) for different free stream air speeds. From Figure 14, a limited variation of the drying rate with air speed is found for a gypsum board with a paper liner, except at very low air speeds. At these very low air speeds, the resistance to vapour transfer of the boundary layer has the same order of magnitude as that of the paper liner, leading to a decrease in drying rate. The scaled drying rate curves, as a function of scaled time, all coincided (not shown here), except that for $U_{\infty}=1$ $\mathrm{m} / \mathrm{s}$. From Figure 14b, the CDRP drying rate of the gypsum board without a paper liner clearly indicates a power law dependency with the air speed, with an exponent equal to 0.8 , which is directly related to the CHTC dependency on the air speed in Eq.(3). Since the influence of the turbulence intensity on the CHTC magnitude is similar to that of the air speed, as indicated in Figure 10, an increased turbulence level will also have a limited effect on gypsum board drying if a paper liner is present and is therefore not considered here.

\subsubsection{Approach flow temperature}

The influence of the approach flow temperature on gypsum board drying is shown in Figure 15 (1D model with constant CTCs at $U_{\infty}=10 \mathrm{~m} / \mathrm{s}$ ). The CDRP drying rates increase with increasing temperature (Figure 15b) for boards with and without a paper liner. A quasi linear increase is found for a gypsum board without a paper liner. The board with a paper liner shows a strong non linear increase with temperature, which can be explained as follows. The large vapour resistance of the paper liner leads to a much lower CDRP drying rate, compared to a 
Defraeye T., Houvenaghel G., Carmeliet J., Derome D. (2012), Numerical analysis of convective drying of gypsum boards, International Journal of Heat and Mass Transfer 55 (9-10), 2590-2600. http://dx.doi.org/10.1016/j.ijheatmasstransfer.2012.01.001

gypsum board without a paper liner. Thereby less (latent) heat is required for the evaporation of liquid water (per unit time), resulting in higher gypsum board temperatures during the CDRP. These higher temperatures result in higher vapour pressures underneath the paper liner ( $p_{v, B P L}$, compared to those at the surface of GB w/o paper), which are equal to the saturation vapour pressure since $\mathrm{RH} \approx 100 \%$ during the CDRP. Together with the approach flow conditions, this vapour pressure $\left(p_{v, B P L}\right)$ determines the amount of moisture removal from the gypsum board by vapour transport through the paper liner and the boundary layer: $g_{w}=\left(p_{v, B P L}-p_{v, a f}\right) /\left(R_{P L}+R_{B L}\right)$. Due to the exponential dependency of this saturation vapour pressure $\left(p_{v, B P L}\right)$ on the temperature and due to the higher gypsum board temperatures (compared to GB w/o paper), the vapour pressure difference $\left(p_{v, B P L}-p_{v, a f}\right)$ and thus the CDRP drying rates $\left(g_{w}\right)$ increase more strongly (non linearly) with increasing approach flow temperatures, as confirmed in Figure 15b. The strong increase of the CDRP drying rate with temperature for boards with a paper liner is thereby mainly temperature related and not related to a varying vapour diffusion resistance of the paper liner $\left(R_{P L}=d_{P L} / \delta_{v, P L}\right)$, due to its dependency on the RH (see Figure 4).

The drying processes for a gypsum board with a paper liner clearly changes with the approach flow temperature (Figure 15a) since the initial transition period, i.e. for the board to go to the CDRP at wet bulb temperature, is much longer for high temperatures, due to the low initial temperature $\left(20^{\circ} \mathrm{C}\right)$ of the board. Note that the HAM model results at the higher temperatures, yet below the boiling point, are only indicative of trends. Certainty in their accuracy could come with material properties which are determined experimentally at higher temperatures than $20^{\circ} \mathrm{C}$.

\section{Discussion towards modelling of an industrial drier}

The study presented in this paper provides a solid base for establishing the methodology for the more complex situation of convective drying of freshly-cured gypsum boards in an industrial drier, which was described in section 2. Some aspects left untouched in this study will have to be considered additionally in such follow-up studies. First of all, the porous-material model should be able to account for higher temperatures, which implies a determination of the material properties at elevated temperatures (close to the boiling point of water). Due to the importance of the paper liner on the drying process, the focus should be especially on its material properties and thickness. Furthermore, for the numerical model used in this study (see section 3.3), the assumptions which limit its use to low temperatures should be alleviated. Particularly, liquid transfer due to thermal gradients will probably not be negligible anymore. Furthermore, several fluid properties (e.g. density of water) and thermodynamic relations will have to be adjusted to account for higher temperatures. Specific details on multiphase transport modelling of porous media at high temperature can be found in e.g. [25-26].

Given the conclusions of this study, air flow modelling is considered to be of less importance due to the large resistance of the paper liner to mass transfer, which is restricting the drying rate. Thereby, detailed threedimensional modelling of the entire drier system, including the complex turbulent flow conditions at the inflow from the sides, is not considered to be required and the use of standard CTC (e.g. from flat plate correlations), which account for the flow field as a function of air speed, is considered to be sufficient. However, the choice of the applied reference conditions (Eqs.(1)-(2)) which are used together with the CTCs is critical here: as the dry air, which is blown in the channels in between the boards, becomes more saturated with moisture and cools 
Defraeye T., Houvenaghel G., Carmeliet J., Derome D. (2012), Numerical analysis of convective drying of gypsum boards, International Journal of Heat and Mass Transfer 55 (9-10), 2590-2600. http://dx.doi.org/10.1016/j.ijheatmasstransfer.2012.01.001

down (due to latent heat effects) as it moves towards the inlet and outlet of the drier, CTCs based on reference conditions at the inlet seem less appropriate. A dependency of the CTCs or of the reference conditions on the location in the drier should be included. For example, these reference conditions could be taken at the centre of the channel in between the boards, which could be determined experimentally or from simple (2D) air flow modelling.

\section{Conclusions}

Convective drying of wet gypsum boards was investigated numerically from the perspective of optimising gypsum board manufacturing by means of a simple configuration at ambient temperatures. The influence of several gypsum board and air flow related parameters on the drying process was investigated. Numerical simulation of the gypsum layer covered with a paper liner resulted in a significant reduction of the gypsum drying rate compared to a gypsum layer without paper since, due to the paper's liquid impermeability, only moisture transport by vapour diffusion occurred. Thereby, the paper liner actually leads to an increased resistance to moisture removal from the gypsum board, in addition to the boundary layer resistance. Apart from the approach flow temperature, the sensitivity of the drying process to the flow conditions (air speed, turbulence intensity and flow field, i.e. spatial distribution of CTCs) is therefore found to be limited for a gypsum board with a paper liner. Detailed flow modelling (i.e. of CTCs) is thereby less critical for this specific drying problem. Future studies should rather focus on better characterisation of the material transport properties of the gypsum board components at high temperatures, particularly for the paper liner. Finally, a scaling of the drying rate and drying time with the CDRP drying rate was proposed, which allowed a better comparison of drying rates if they differed significantly in magnitude, e.g. due to a different approach flow air speed. Note that gypsum board is a typical layered composite material, where only vapour (and no liquid) transfer occurs in the outer layer (paper liner). Therefore the findings of this study can also be relevant for convective drying of similar composite materials.

\section{Acknowledgements}

Thijs Defraeye is a postdoctoral fellow of the Research Foundation - Flanders (FWO) and acknowledges its support.

\section{$\underline{\text { References }}$}

[1] O. Axenenko, G. Thorpe, The modelling of dehydration and stress analysis of gypsum plasterboards exposed to fire, Computational Materials Science 6 (3) (1996) 281-294.

[2] C.N. Ang, Y.C. Wang, The effect of water movement on specific heat of gypsum plasterboard in heat transfer analysis under natural fire exposure, Construction and Building Materials 18 (7) (2004) 505-515.

[3] A. Belmiloudi, G. Le Meur, Mathematical and numerical analysis of dehydratation of gypsum plasterboards exposed to fire, Applied Mathematics and Computation 163 (3) (2005) 1023-1041.

[4] K. Ghazi Wakili, E. Hugi, L. Wullschleger, T.H. Frank, Gypsum board in fire - Modeling and experimental validation, Journal of Fire Sciences 25 (3) (2007) 267-282.

[5] S.T. Craft, B. Isgor, G. Hadjisophocleous, J.R. Mehaffey, Predicting the thermal response of gypsum board subjected to a constant heat flux, Fire and Materials 32 (6) (2008) 333-355. 
Defraeye T., Houvenaghel G., Carmeliet J., Derome D. (2012), Numerical analysis of convective drying of gypsum boards, International Journal of Heat and Mass Transfer 55 (9-10), 2590-2600. http://dx.doi.org/10.1016/j.ijheatmasstransfer.2012.01.001

[6] C.N. Ang, Y.C. Wang, Effect of moisture transfer on specific heat of gypsum plasterboard at high temperatures, Construction and Building Materials 23 (2) (2009) 675-686.

[7] K. Ghazi Wakili, E. Hugi, Four types of gypsum plaster boards and their thermophysical properties under fire condition, Journal of Fire Sciences 27 (1) (2009) 27-43.

[8] D. Kontogeorgos, M. Founti, Numerical investigation of simultaneous heat and mass transfer mechanisms occurring in a gypsum board exposed to fire conditions, Applied Thermal Engineering 30 (11-12) (2010) 1461-1469.

[9] S.V. Shepel, K. Ghazi Wakili, E. Hugi, Vapor convection in gypsum plasterboard exposed to fire: Numerical simulation and validation, Numerical Heat Transfer, Part A: Applications 57 (12) (2010) 911-935.

[10] S. Szentgyörgyi, L. Tömösy, O. Molnar, Convective heat transfer coefficients at convective drying of porous materials, Drying Technology 18 (6) (2000) 1287-1304.

[11] M. Prat, Percolation model of drying under isothermal conditions in porous media, International Journal of Multiphase Flow 19 (4) (1993) 691-704.

[12] J. Carmeliet, F. Descamps, G. Houvenaghel, A multiscale network model for simulating moisture transfer properties of porous media, Transport in Porous Media 35 (1999) 67-88.

[13] A.G. Yiotis, A.K. Stubos, A.G. Boudouvis, Y.C. Yortsos, A 2-D pore-network model of the drying of single-component liquids in porous media, Advances in Water Resources 24 (3-4) (2001) 439-460.

[14] S. Ben Nasrallah, P. Perre, Detailed study of a model of heat and mass transfer during convective drying of porous media, International Journal of Heat and Mass Transfer 31 (5) (1988) 957-967.

[15] H. Janssen, B. Blocken, J. Carmeliet, Conservative modelling of the moisture and heat transfer in building components under atmospheric excitation, International Journal of Heat and Mass Transfer 50 (5-6) (2007) 1128-1140.

[16] J.H. Lienhard IV, J.H. Lienhard V, A Heat Transfer Textbook, third ed., Phlogiston Press, Cambridge Massachusetts, USA, 2006.

[17] T.H. Shih, W.W. Liou, A. Shabbir, Z. Yang, J. Zhu, A new k- $\varepsilon$ eddy viscosity model for high Reynolds number turbulent flows, Computers \& Fluids 24 (3) (1995) 227-238.

[18] M. Wolfshtein, The velocity and temperature distribution in one-dimensional flow with turbulence augmentation and pressure gradient, International Journal of Heat and Mass Transfer 12 (3) (1969) 301318.

[19] B.E. Launder, D.B. Spalding, The numerical computation of turbulent flows, Computer Methods in Applied Mechanics and Engineering 3 (2) (1974) 269-289.

[20] Launder B.E., On the computation of convective heat transfer in complex turbulent flows, Transactions of the ASME: Journal of Heat Transfer 110 (1988) 1112-1128.

[21] B. Blocken, T. Defraeye, D. Derome, J. Carmeliet, High-resolution CFD simulations for forced convective heat transfer coefficients at the facade of a low-rise building, Building and Environment 44 (12) (2009) 2396-2412.

[22] T. Defraeye, B. Blocken, J. Carmeliet, CFD analysis of convective heat transfer at the surfaces of a cube immersed in a turbulent boundary layer, International Journal of Heat and Mass Transfer 53 (1-3) (2010) 297-308. 
Defraeye T., Houvenaghel G., Carmeliet J., Derome D. (2012), Numerical analysis of convective drying of gypsum boards, International Journal of Heat and Mass Transfer 55 (9-10), 2590-2600. http://dx.doi.org/10.1016/j.ijheatmasstransfer.2012.01.001

[23] S. Roels, J. Carmeliet, H. Hens, O. Adan, H. Brocken, R. Cerny, Z. Pavlik, C. Hall, K. Kumaran, L. Pel, R. Plagge, Interlaboratory comparison of hygric properties of porous building materials, Journal of Thermal Envelope and Building Science 27 (2004) 307-325.

[24] J. Carmeliet, S. Roels, Determination of the isothermal moisture transport properties of porous building materials, Journal of Thermal Envelope and Building Science 24 (3) (2001) 183-210.

[25] D. Gawin, F. Pesavento, B.A. Schrefler, Modelling of hygro-thermal behaviour of concrete at high temperature with thermo-chemical and mechanical material degradation, Computer Methods in Applied Mechanics and Engineering 192 (13-14) (2003) 1731-1771.

[26] D. Gawin, F. Pesavento, B.A. Schrefler, Modelling damage processes of concrete at high temperature with thermodynamics of multiphase porous media, Journal of Theoretical and Applied Mechanics 44 (3) (2006) 505-532. 
Defraeye T., Houvenaghel G., Carmeliet J., Derome D. (2012), Numerical analysis of convective drying of gypsum boards, International Journal of Heat and Mass Transfer 55 (9-10), 2590-2600. http://dx.doi.org/10.1016/j.ijheatmasstransfer.2012.01.001

Figures

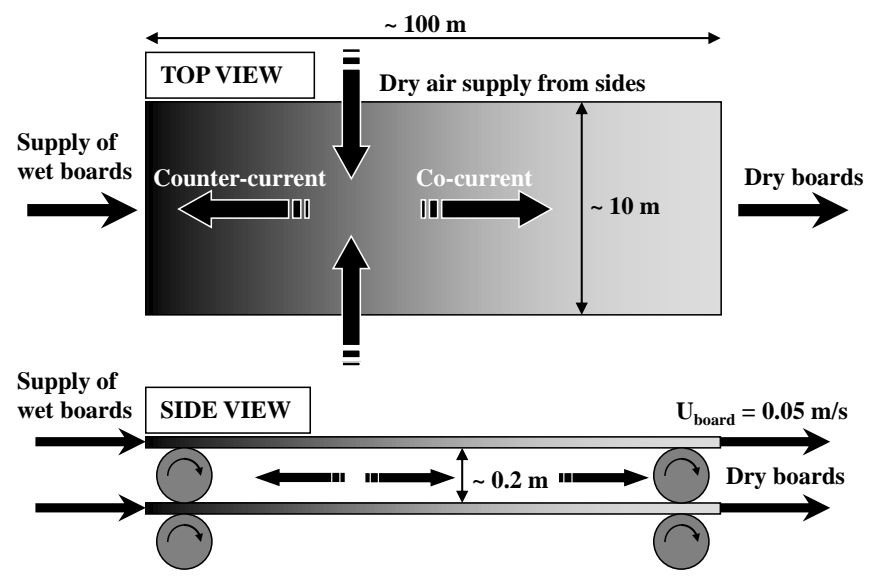

Figure 1. Schematic representation of industrial gypsum-board drier (not to scale, total drier length $\approx 100$ m). 
Defraeye T., Houvenaghel G., Carmeliet J., Derome D. (2012), Numerical analysis of convective drying of gypsum boards, International Journal of Heat and Mass Transfer 55 (9-10), 2590-2600. http://dx.doi.org/10.1016/j.ijheatmasstransfer.2012.01.001

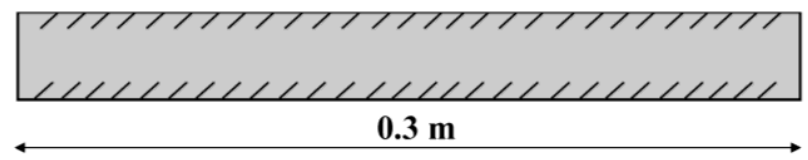

\section{Symmetry plane}

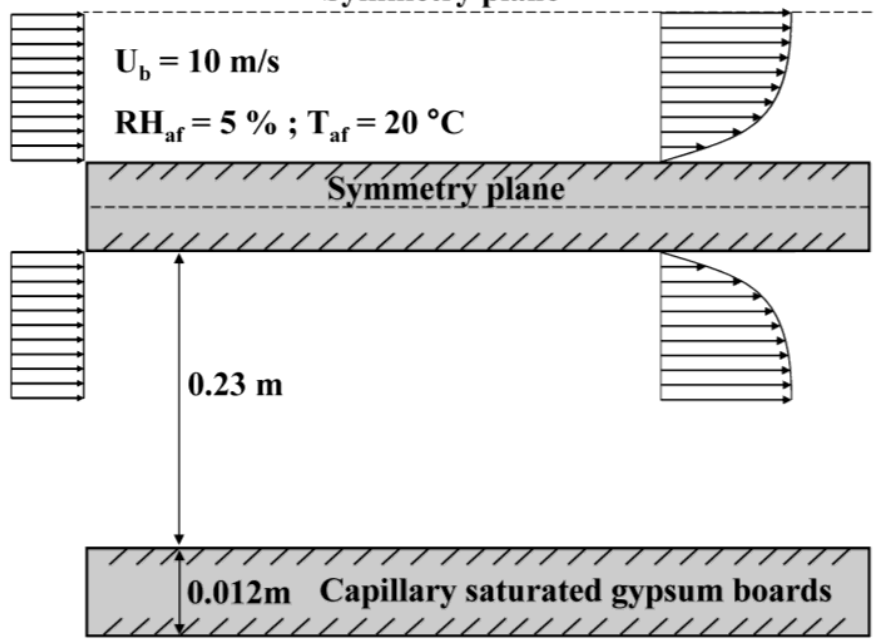

Figure 2. Simple two-dimensional configuration with indication of symmetry planes. 
Defraeye T., Houvenaghel G., Carmeliet J., Derome D. (2012), Numerical analysis of convective drying of gypsum boards, International Journal of Heat and Mass Transfer 55 (9-10), 2590-2600. http://dx.doi.org/10.1016/j.ijheatmasstransfer.2012.01.001

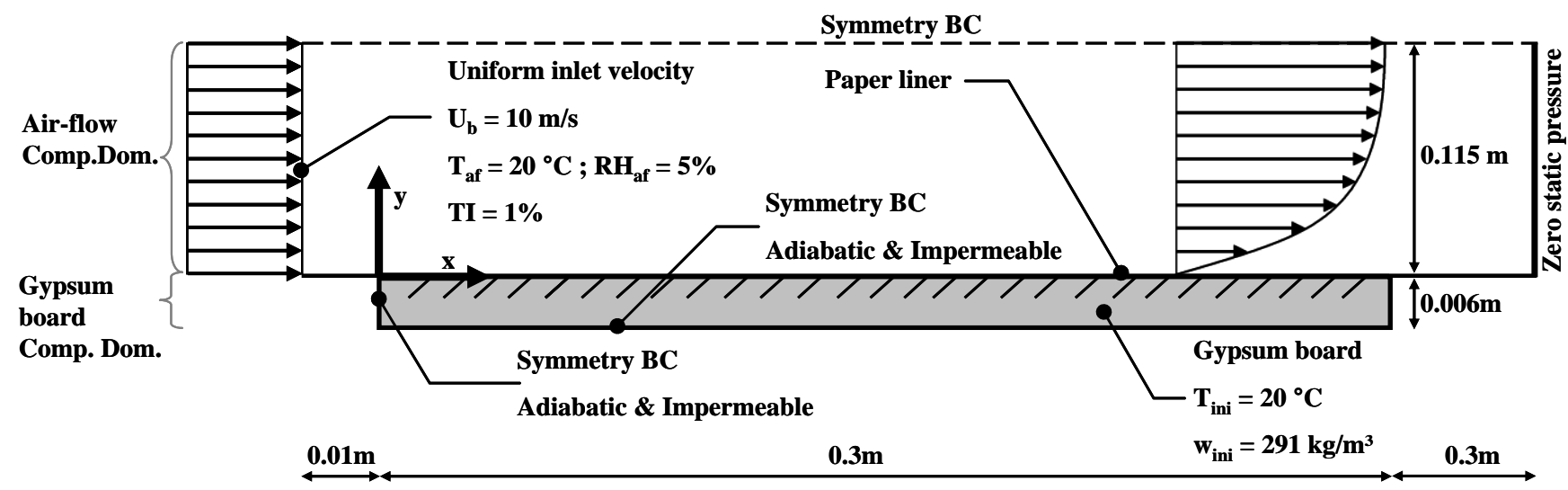

Figure 3. Computational model for numerical analysis for gypsum board and air flow (not to scale; BC: boundary conditions; Comp. Dom: computational domain; in: initial conditions; TI: turbulence intensity) 
Defraeye T., Houvenaghel G., Carmeliet J., Derome D. (2012), Numerical analysis of convective drying of gypsum boards, International Journal of Heat and Mass Transfer 55 (9-10), 2590-2600.

http://dx.doi.org/10.1016/j.jiheatmasstransfer.2012.01.001
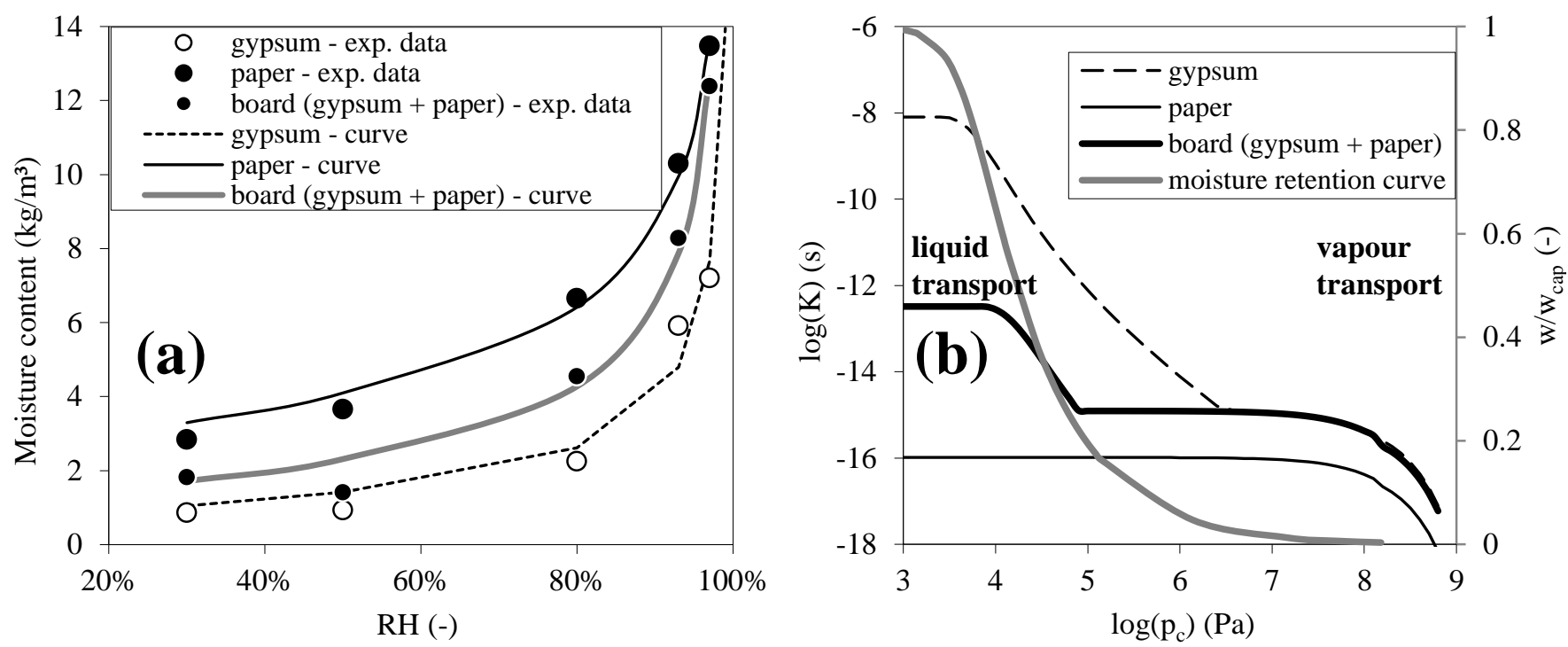

Figure 4. (a) Measured sorption curves (moisture content as a function of relative humidity) of paper, gypsum and gypsum board, which approximate the experimental data (exp. data); (b) Calculated logarithm of the moisture permeability $(K)$ as a function of the logarithm of the capillary pressure for paper, gypsum and gypsum board, based on measured sorption curves, vapour permeability and liquid water uptake. The moisture retention curve, scaled with $w_{c a p}$, is also included. 
Defraeye T., Houvenaghel G., Carmeliet J., Derome D. (2012), Numerical analysis of convective drying of gypsum boards, International Journal of Heat and Mass Transfer 55 (9-10), 2590-2600.

http://dx.doi.org/10.1016/j.ijheatmasstransfer.2012.01.001
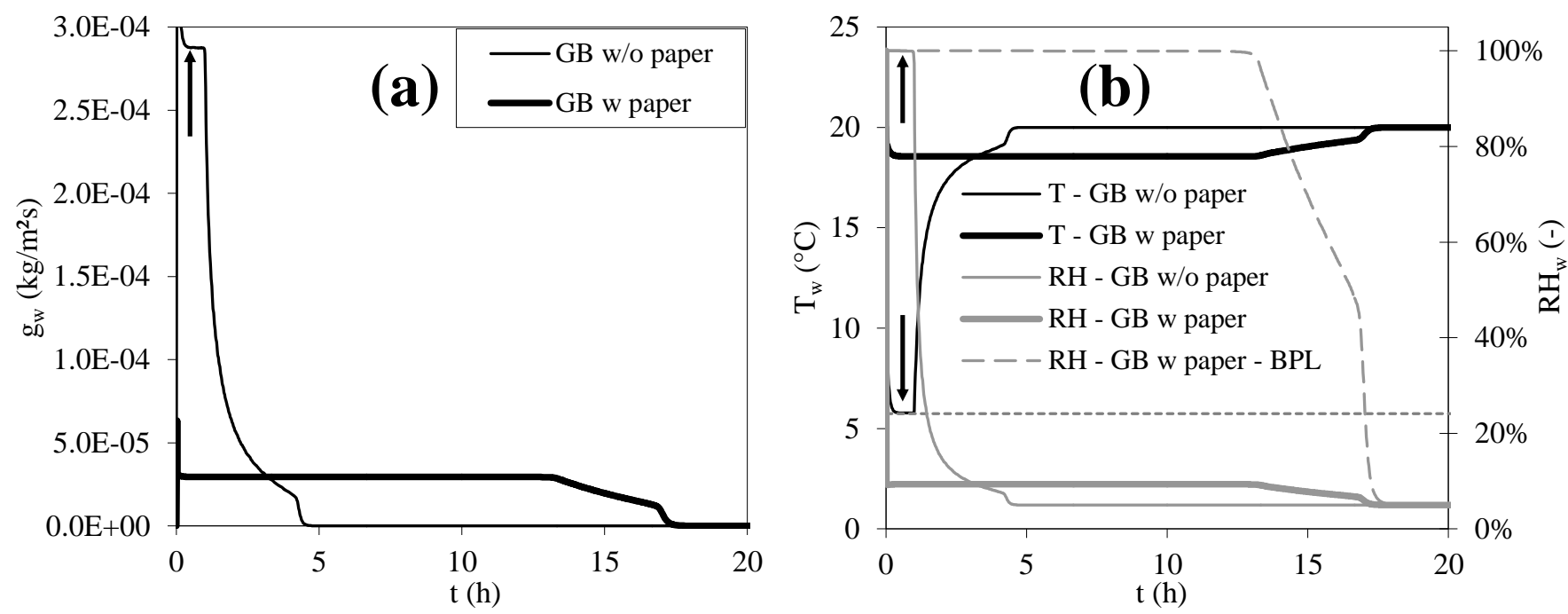

Figure 5. Comparison of drying of gypsum board with and without paper liner as a function of time (1D model, constant CTCs): (a) Drying rate; (b) Surface temperature and RH (BPL indicates the RH below the paper liner $(y=-\mathbf{0 . 0 0 0 2 7} \mathrm{m}$ ); the arrows indicate the CDRP for GB w/o paper; the horizontal dotted grey line indicates the wet bulb temperature). 
Defraeye T., Houvenaghel G., Carmeliet J., Derome D. (2012), Numerical analysis of convective drying of gypsum boards, International Journal of Heat and Mass Transfer 55 (9-10), 2590-2600. http://dx.doi.org/10.1016/j.ijheatmasstransfer.2012.01.001
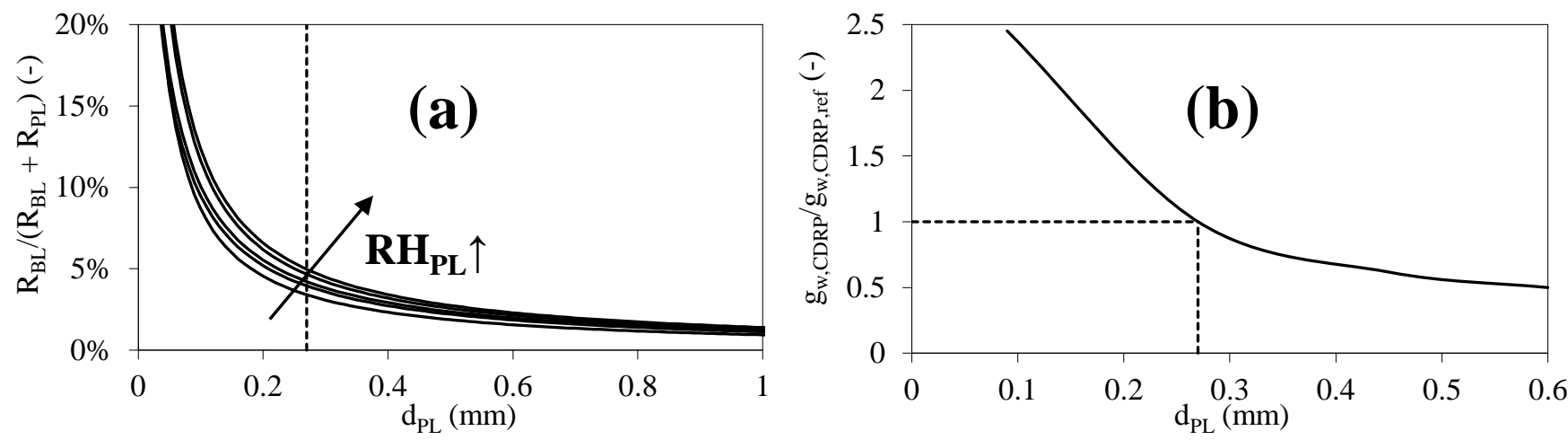

Figure 6. (a) Boundary layer vapour transfer resistance, normalised with the resistance of the boundary layer and the paper liner, as a function of the paper liner thickness for different relative humidity of the paper liner (20\% $\left.\leq R H_{P L} \leq 100 \%\right)$; (b) CDRP drying rate of the gypsum board, normalised with the CDRP drying rate for a paper liner of $0.27 \mathrm{~mm}$, as a function of the paper liner thickness (1D model, constant CTCs, $U_{\infty}=10 \mathrm{~m} / \mathrm{s}$ ). 
Defraeye T., Houvenaghel G., Carmeliet J., Derome D. (2012), Numerical analysis of convective drying of gypsum boards, International Journal of Heat and Mass Transfer 55 (9-10), 2590-2600. http://dx.doi.org/10.1016/j.ijheatmasstransfer.2012.01.001

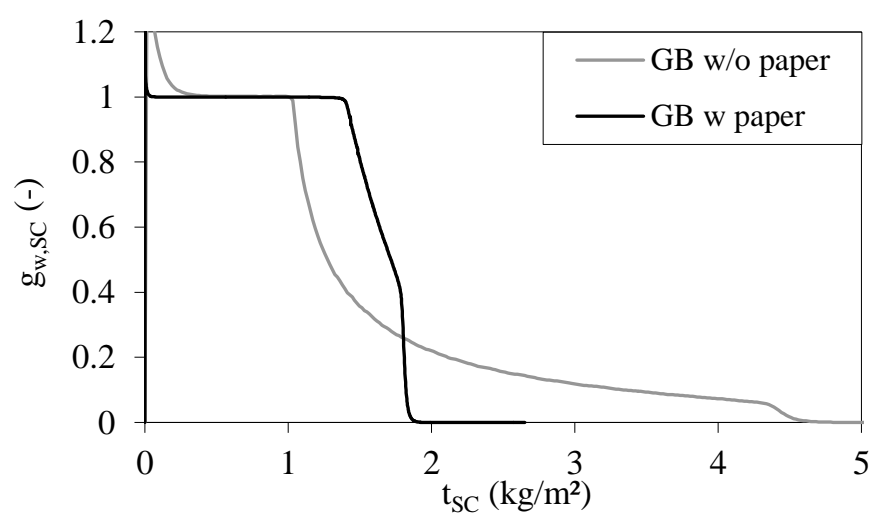

Figure 7. Drying rate, scaled with the CDRP drying rate, as a function of scaled time, i.e. multiplied by the CDRP drying rate, of gypsum board with and without a paper liner (1D model, constant CTCs). 
Defraeye T., Houvenaghel G., Carmeliet J., Derome D. (2012), Numerical analysis of convective drying of gypsum boards, International Journal of Heat and Mass Transfer 55 (9-10), 2590-2600. http://dx.doi.org/10.1016/j.ijheatmasstransfer.2012.01.001
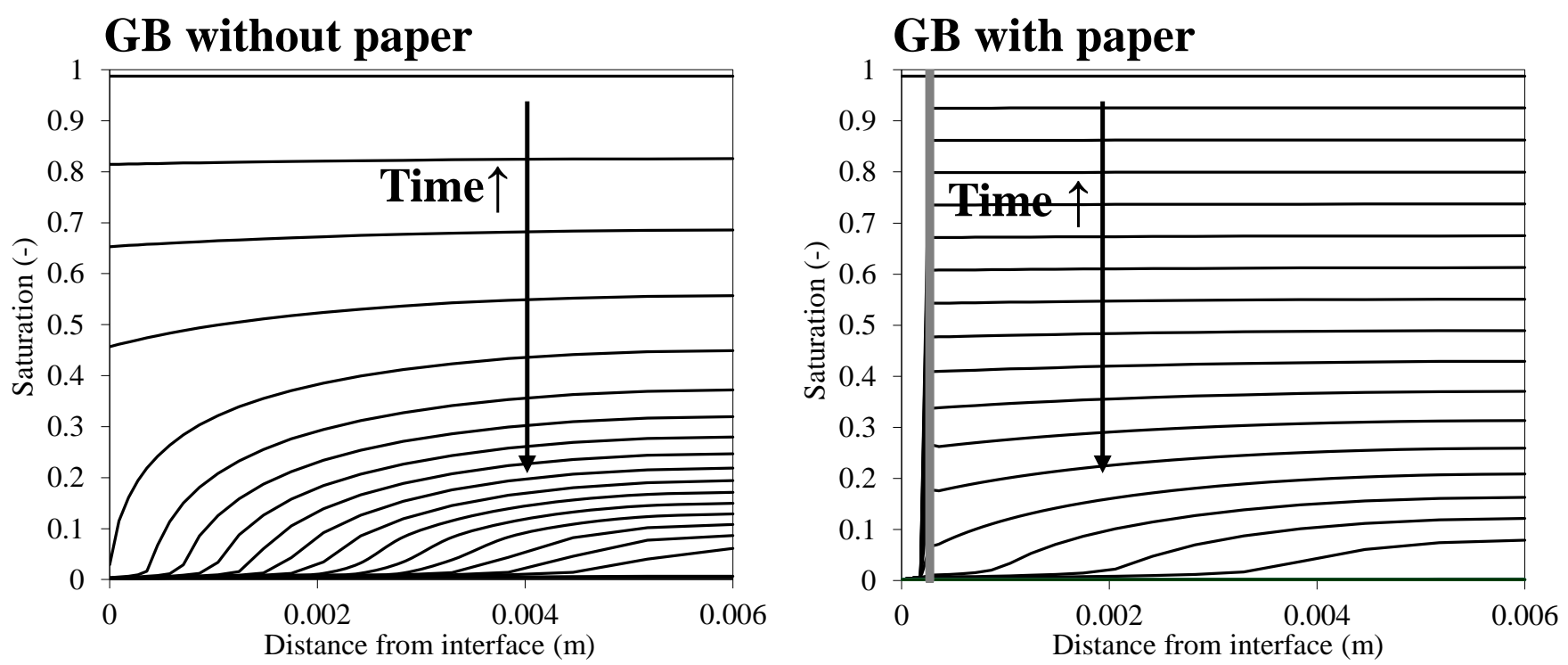

Figure 8. Moisture saturation level in the gypsum board (1D model, constant CTCs) of gypsum board with and without a paper liner as a function of the distance from the interface for different moments in time. 
Defraeye T., Houvenaghel G., Carmeliet J., Derome D. (2012), Numerical analysis of convective drying of gypsum boards, International Journal of Heat and Mass Transfer 55 (9-10), 2590-2600. http://dx.doi.org/10.1016/j.ijheatmasstransfer.2012.01.001

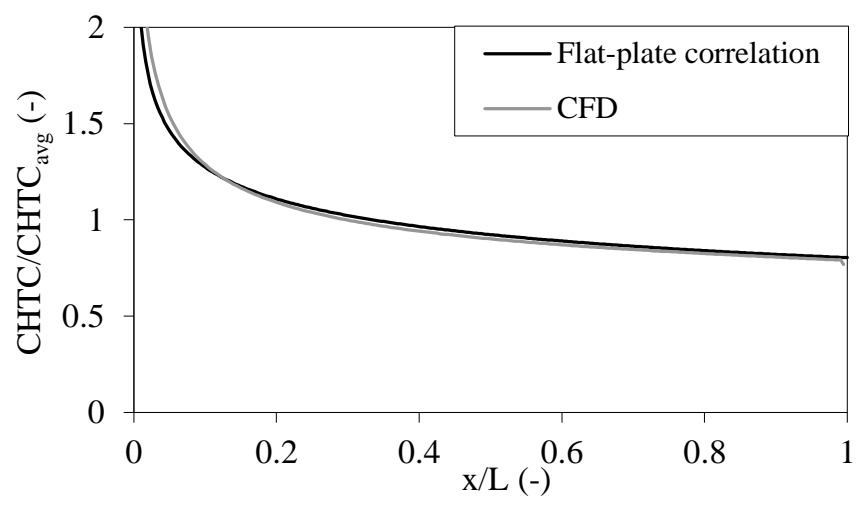

Figure 9. CHTC, normalised by the average CHTC over the surface, for a flat plate correlation (Eq.(3)) and CFD as a function of the dimensionless distance along the gypsum board (1D model, constant CTCs). 
Defraeye T., Houvenaghel G., Carmeliet J., Derome D. (2012), Numerical analysis of convective drying of gypsum boards, International Journal of Heat and Mass Transfer 55 (9-10), 2590-2600.

http://dx.doi.org/10.1016/j.ijheatmasstransfer.2012.01.001
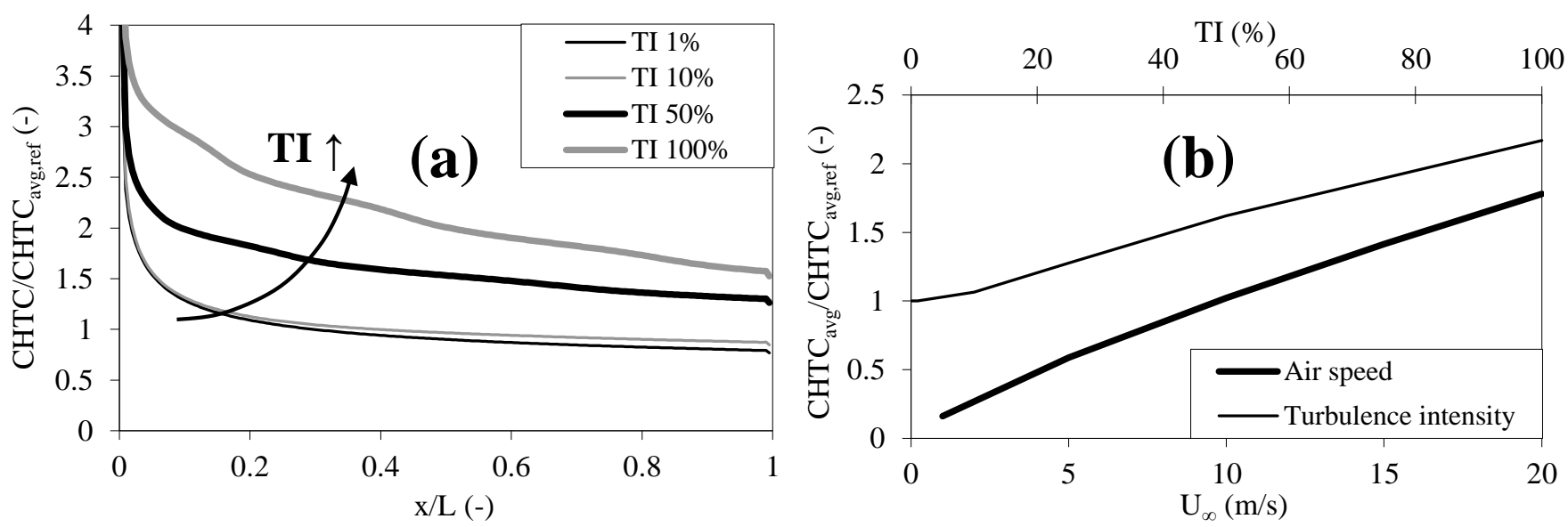

Figure 10. (a) CHTC distribution of CFD (at $10 \mathrm{~m} / \mathrm{s}$ ) at different inlet turbulence intensities, as a function of the dimensionless distance along the board; (b) Surface-averaged CHTCs of CFD as a function of the turbulence intensity and of the free stream air speed. The CHTCs are normalised by the surface-averaged CHTC for a turbulence intensity of $1 \%$ at $U_{\infty}=10 \mathrm{~m} / \mathrm{s}$ (reference case). 
Defraeye T., Houvenaghel G., Carmeliet J., Derome D. (2012), Numerical analysis of convective drying of gypsum boards, International Journal of Heat and Mass Transfer 55 (9-10), 2590-2600. http://dx.doi.org/10.1016/j.ijheatmasstransfer.2012.01.001

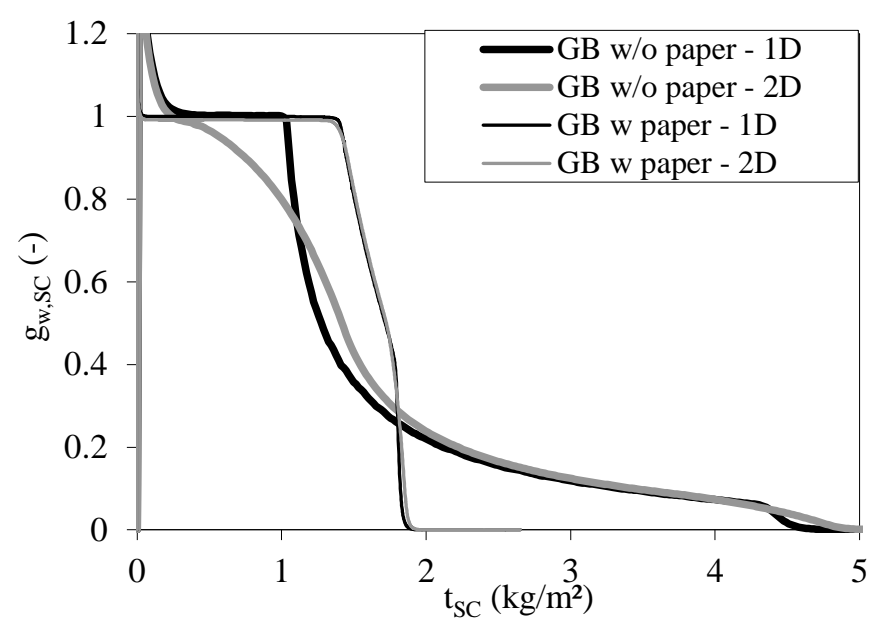

Figure 11. Scaled drying rate of gypsum board with and without a paper liner for 1D and 2D HAM modelling, as a function of scaled time. The drying rates and times of the 2D simulation are scaled with the $g_{w, C D R P}$ of the $1 \mathrm{D}$ simulation. 
Defraeye T., Houvenaghel G., Carmeliet J., Derome D. (2012), Numerical analysis of convective drying of gypsum boards, International Journal of Heat and Mass Transfer 55 (9-10), 2590-2600.

http://dx.doi.org/10.1016/j.ijheatmasstransfer.2012.01.001
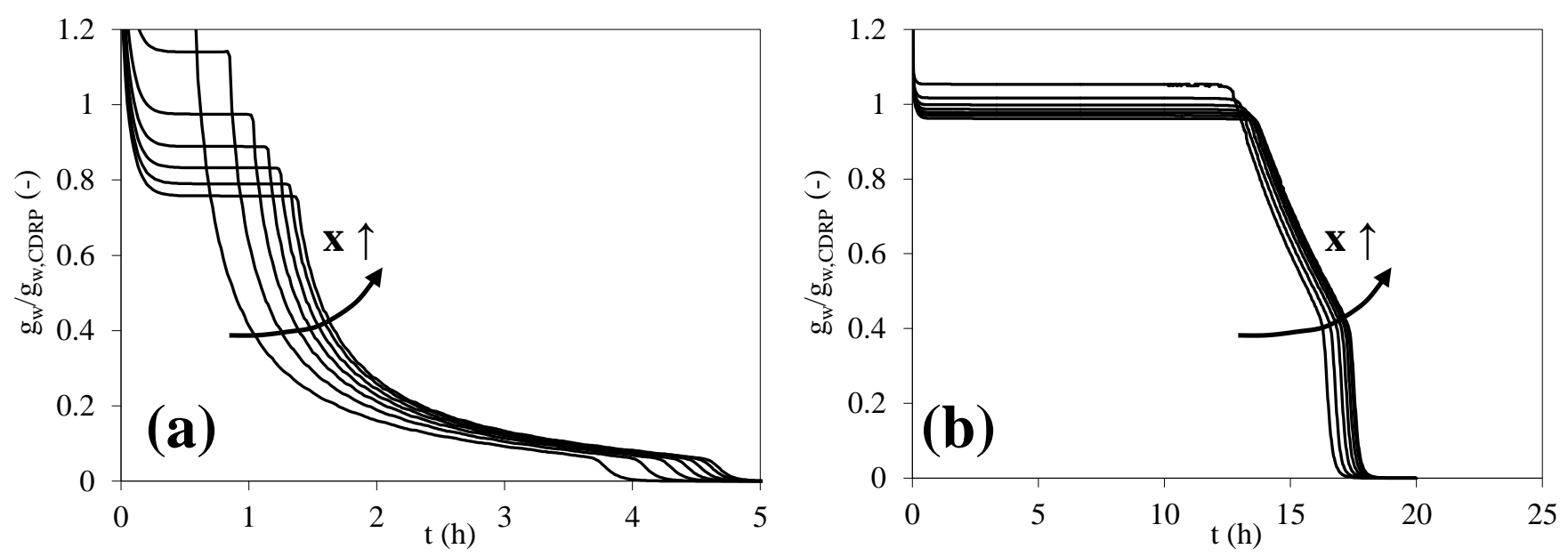

Figure 12. Drying rate of gypsum board without (a) and with a paper liner (b) for 2D HAM modelling, normalised with the CDRP drying rate $\left(g_{w, C D R P}\right)$ of the 1D simulation, as a function of time at different locations ( $x$ coordinate) on the gypsum board surface (see Figure 3). 
Defraeye T., Houvenaghel G., Carmeliet J., Derome D. (2012), Numerical analysis of convective drying of gypsum boards, International Journal of Heat and Mass Transfer 55 (9-10), 2590-2600. http://dx.doi.org/10.1016/j.ijheatmasstransfer.2012.01.001

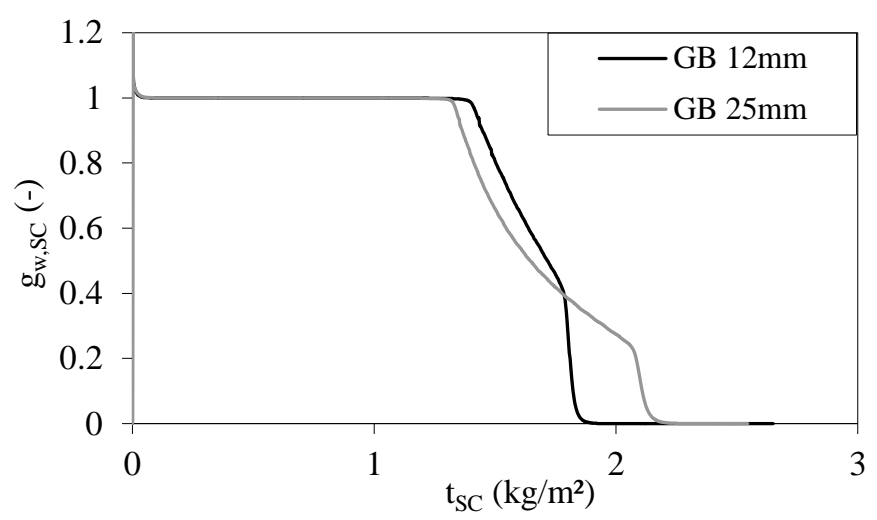

Figure 13. Scaled drying rate of gypsum board with paper, as a function of scaled time, for a board thickness of $12 \mathrm{~mm}$ and $25 \mathrm{~mm}$. The scaled time of the $25 \mathrm{~mm}$ board is also scaled with a factor 12/25 to account for the larger initial moisture content (1D model, constant CTCs). 
Defraeye T., Houvenaghel G., Carmeliet J., Derome D. (2012), Numerical analysis of convective drying of gypsum boards, International Journal of Heat and Mass Transfer 55 (9-10), 2590-2600. http://dx.doi.org/10.1016/j.ijheatmasstransfer.2012.01.001
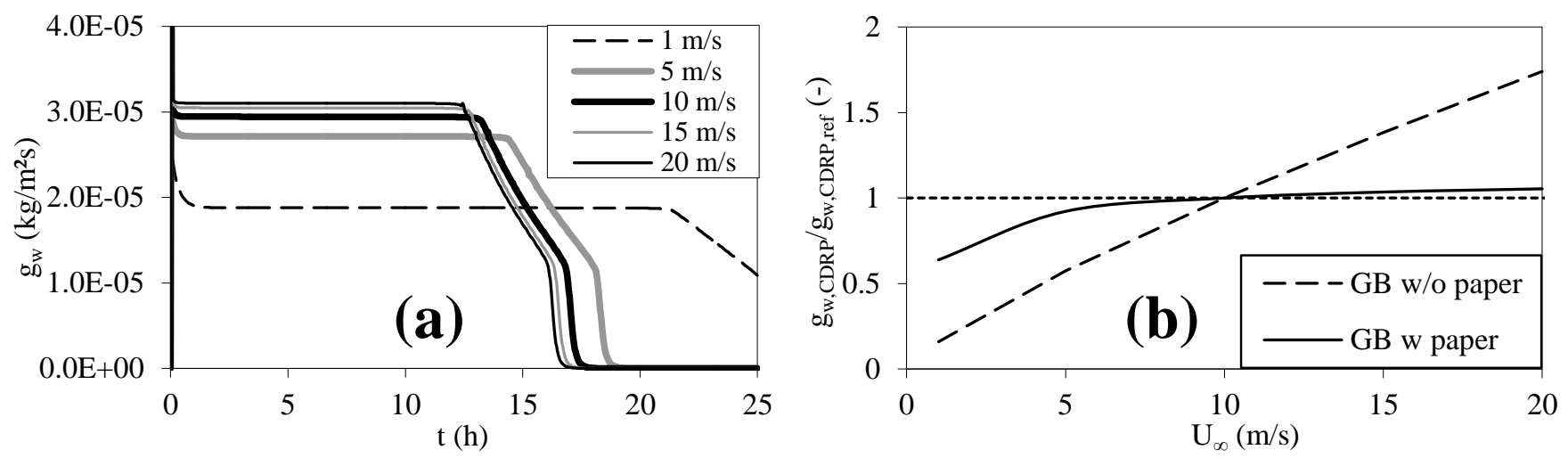

Figure 14. (a) Drying rate of gypsum board with a paper liner at different free stream air speeds, as a function of time; (b) CDRP drying rate of gypsum board with and without a paper liner, normalised with the CDRP drying rate for a gypsum board at $U_{\infty}=10 \mathrm{~m} / \mathrm{s}$ (reference case), as a function of the free stream air speed (1D model, constant CTCs). 
Defraeye T., Houvenaghel G., Carmeliet J., Derome D. (2012), Numerical analysis of convective drying of gypsum boards, International Journal of Heat and Mass Transfer 55 (9-10), 2590-2600.

http://dx.doi.org/10.1016/j.ijheatmasstransfer.2012.01.001
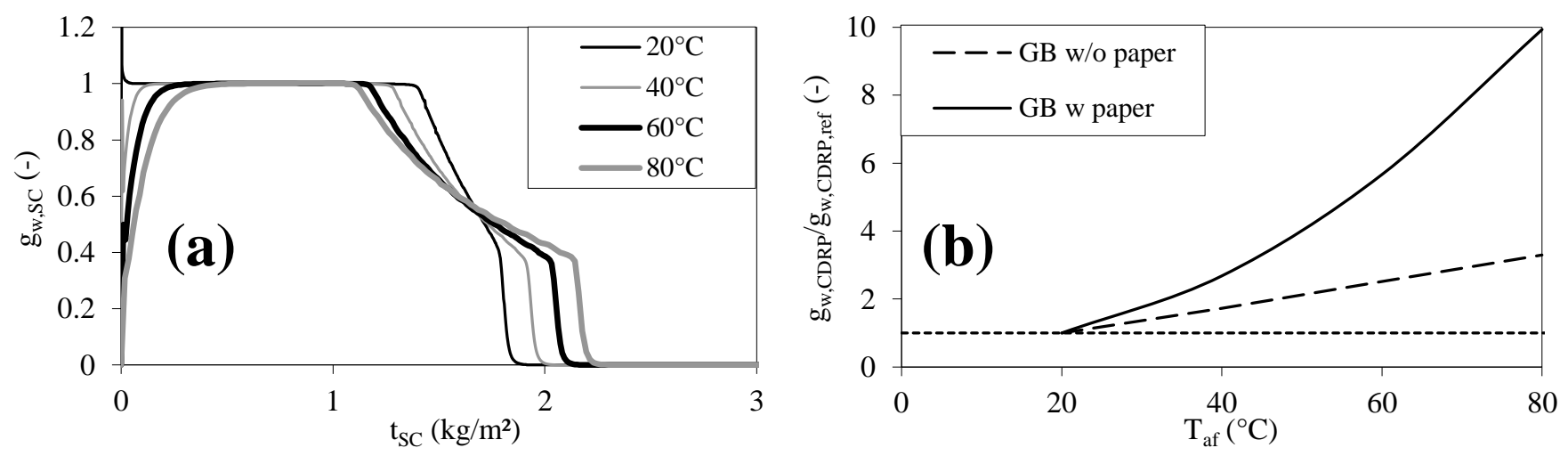

Figure 15. (a) Scaled drying rate of gypsum board with a paper liner at different approach flow

temperatures, as a function of scaled time; (b) CDRP drying rate of gypsum board with and without a paper liner, normalised with the CDRP drying rate for a gypsum board at $T_{a f}=20^{\circ} \mathrm{C}$ (reference case), as a function of the approach flow temperature (1D model, constant CTCs). 